\title{
The Bilateral Occurrence of Caries in First Permanent Molaramong 7-12 Years Old Children Attending Dental Hospital/ College of Dentistry, University of Baghdad
}

\author{
Rusul J. Haddi ${ }^{1}$, Dina Hamid Obaid ${ }^{2}$ \\ ${ }^{1}$ Department of Pedodontic and Preventive Dentistry, College of Dentistry, University of Baghdad, Iraq \\ ${ }^{2}$ Department of Orthodontic, College of Dentistry, University of Baghdad, Iraq
}

\begin{abstract}
Aim of study: The purpose of the present study was to determine the severity and bilateral occurrence of caries in first permanent molar among 7-12 years old children attending Dental Hospital/ College of Dentistry, University of Baghdad.Material and method:The total sample composed 100 children (55 boys and 45girls) with an age (7-12) years. Those children were attending the Prevention and Pedodontics dental clinic in the College of Dentistry, Baghdad University as a first visit.Information regarding the name, age and gender of the patient was registered prior to the examination.Oral examination were carried out according to the criteria of (WHO 1997).The diagnosis of dental caries was carried out according to the criteria of Manji et al1989.This allows recording decayed lesion by severity. Result: The occurrence of caries was the highest percentage on left side73\% than right side (69\%) for maxillary teeth while in mandibular teeth the higher percentage was on the right side $(92 \%)$ than the left side $(82 \%)$. $D_{2}$ was the highest among mandibular and maxillary teeth for both sides in all age group while $D_{4}$ was the lowest percentage. The bilateral occurrence of caries was higher in lower jaw (80\%) than upper jaw (64\%). Concerning the occurrence of bilateral caries severity $D_{2}$ registered the highest percentage for upper and lower jaw (26\%-20\%) respectively. Conclusion: A high bilateral occurrence demands careful prevention strategies including fissure sealants, topical fluoride applications.The knowledge of caries pattern would help clinicians in the formulation of appropriate treatment strategies.
\end{abstract}

Keywords: Bilateral occurrence,Severity, First permanent molar, Children

\section{Introduction}

Dental caries is one of the most common oral diseases; it is a major problem in dentistry and should receive significant attention from restorative and preventive stand point [1].

The first permanent molar is unquestionably the most important unit of mastication and is essential in the development of functionally desirable occlusion. The first permanent molars were more susceptible to dental caries and they have the highest caries attack rate among the permanent dentition. The molar teeth have many grooves (fissures) and pits on the chewing (occlusal) surfaces and on the buccal and palatal surfaces, which can be very difficult to keep clean. These sites are most susceptible to developing decay $[2]$.

Knowledge of caries patterns in a population assists in the prevention and diagnosis of dental caries. A bilaterally symmetrical pattern in the occurrence of dental caries has been reported previously by several researchers around the world; however, the observations have been confined to equal or similar level of caries experience on both sides of the mouth. Brekhus in 1928 first noted the bilateral pattern of tooth mortality due to caries[3]. Knutson and Klein in 1938 recognized that tooth eruption and occurrence of caries in teeth are symmetrical and bilaterally equal [4]. Halikis in 1965 also reported the bilaterally of dental caries in both permanent and deciduous dentition of Australian children in [5]. Several studies concerning the primary teeth were reported a bilateral occurrence of caries in preschool children $[6,7,8]$.Wyne in 2004also reported that caries bilaterally and the conditional probability for bilateral caries occurrence was high in the study population [9]. Sadeghiin 2007 also reported bilateral caries occurrence in the first permanent molars was concluded to be high in the study population[10].There are no previous Iraqi studies concerning the bilateral occurrence of caries in first permanent molar so this present study is conducted.

\section{Materials and Method}

The total sample composed 100 children (55 boys and 45girls) with an age 7-12 years divided into three age groups. Those children were attending the Prevention and Pedodontics dental clinic of the College of Dentistry, University of Baghdad. Information regarding the name, age and gender of the patient was registered prior to the examination. . The field examiner was trained and calibrated with a senior faculty from Baghdad university college of dentistry.Oral examination were carried out under the standardized conditions according to the basic methods of oral health surveys of world health organizationWHO[11]. The dental caries of children were recorded by disposable mouth mirror and dental explorer. The diagnosis of dental caries was carried out according to the criteria of Manji et al [12]. This allows recording decayed lesion by severity.

\section{Results}

The occurrence of caries in relation to age and location are presents in table (1).The result showed that for the total sample the occurrence of caries was more on left side than

\section{Volume 6 Issue 12, December 2017}




\section{International Journal of Science and Research (IJSR) \\ ISSN (Online): 2319-7064}

Index Copernicus Value (2016): 79.57 | Impact Factor (2015): 6.391

right side for maxillary teeth while opposite result was found in mandibular teeth. Data analysis in each age group showed the same result for maxillary teeth except the younger age as the opposite result found while the mandibular teeth the table showed that for the older age the same percentage found on both right and left while the younger had higher on right however 9-10 had opposite result.

Table 1: The occurrence of dental caries in relation to age and location

\begin{tabular}{|c|c|c|c|c|c|}
\hline \multirow{2}{*}{$\begin{array}{c}\text { Age } \\
\text { groups }\end{array}$} & \multirow{2}{*}{ No. } & \multicolumn{2}{|c|}{$\begin{array}{c}\text { Maxillary } 1^{\text {st }} \\
\text { molar\% }\end{array}$} & \multicolumn{2}{|c|}{$\begin{array}{c}\text { Mandibular } 1^{\text {st }} \\
\text { molar\% }\end{array}$} \\
\cline { 3 - 6 } & & Right & Left & Right & Left \\
\hline $7-8$ & 29 & 44.8 & 37.9 & 89.6 & 58.6 \\
\hline $9-10$ & 24 & 79.1 & 87.5 & 95.8 & 100 \\
\hline $11-12$ & 47 & 78.7 & 87.2 & 89.3 & 89.3 \\
\hline Total & 100 & 69 & 73 & 92 & 82 \\
\hline
\end{tabular}

Table (2) shows the distribution of caries severity. Result showed that for the total sample in maxillary teeth $D_{1}$ was higher in the right side than left side while opposite result for $\mathrm{D}_{2}, \mathrm{D}_{3}, \mathrm{D}_{4}$.In mandibular teeth $\mathrm{D}_{1}, \mathrm{D}_{2}, \mathrm{D}_{3}$ were higher in the right side than left side while opposite result for $\mathrm{D}_{4}$. Concerning each age group $\mathrm{D}_{2}$ had higher percentage in mandibular and maxillary teeth for both side in all age while opposite result was registered concerning $\mathrm{D}_{4}$.

Table 2: The distribution of caries severity in relation to location by age group

\begin{tabular}{|c|c|c|c|c|c|}
\hline $\begin{array}{c}\text { Age } \\
\text { groups }\end{array}$ & variables & \multicolumn{2}{|c|}{ Maxillary $1^{\text {st }}$ molar\% } & \multicolumn{2}{|c|}{$\begin{array}{c}\text { Mandibular } 1^{\text {st }} \\
\text { molar\% }\end{array}$} \\
\cline { 3 - 6 } & & Right & Left & Right & Left \\
\hline \multirow{4}{*}{$7-8$} & $\mathrm{D}_{1}$ & 13.7 & 17.2 & 31 & 10.3 \\
\cline { 2 - 6 } & $\mathrm{D}_{2}$ & 27.5 & 17.2 & 44.8 & 27.5 \\
\cline { 2 - 6 } & $\mathrm{D}_{3}$ & 3.4 & 6.8 & 17.2 & 20.6 \\
\cline { 2 - 6 } & $\mathrm{D}_{4}$ & 3.4 & 3.4 & 3.4 & 0 \\
\hline \multirow{4}{*}{$9-10$} & $\mathrm{D}_{1}$ & 20.8 & 12.5 & 4.1 & 8.3 \\
\cline { 2 - 6 } & $\mathrm{D}_{2}$ & 54.1 & 62.5 & 50 & 45.8 \\
\cline { 2 - 6 } & $\mathrm{D}_{3}$ & 4.1 & 4.1 & 29.1 & 25 \\
\cline { 2 - 6 } & $\mathrm{D}_{4}$ & 0 & 8.3 & 2.5 & 16.6 \\
\hline \multirow{4}{*}{ Total } & $\mathrm{D}_{1}$ & 14.8 & 14.8 & 6.3 & 10.6 \\
\cline { 2 - 6 } & $\mathrm{D}_{2}$ & 40.4 & 48.9 & 44.6 & 38.2 \\
\cline { 2 - 6 } & $\mathrm{D}_{3}$ & 12.7 & 14.8 & 25.5 & 19.1 \\
\cline { 2 - 6 } & $\mathrm{D}_{4}$ & 10.6 & 6.3 & 17 & 23.4 \\
\hline & $\mathrm{D}_{1}$ & 16 & 15 & 13 & 10 \\
\cline { 2 - 6 } & $\mathrm{D}_{2}$ & 40 & 43 & 46 & 37 \\
\cline { 2 - 6 } & $\mathrm{D}_{3}$ & 8 & 10 & 25 & 22 \\
\cline { 2 - 6 } & $\mathrm{D}_{4}$ & 6 & 7 & 12 & 15 \\
\hline
\end{tabular}

Table (3) represents the bilateral occurrence of caries by in the upper and the lower jaw .the result showed for the total sample the caries bilaterally was higher in the lower jaw $80 \%$ than the upper jaw $65 \%$. Concerning each age group showed the same result as the mandibular teeth had higher percentage of bilaterally occurrence of caries however,the highest percentage of bilateraloccurrence was found among the older age group.

Table 3: The bilateral occurrence of caries by age

\begin{tabular}{|c|c|c|}
\hline Age groups & $\begin{array}{c}\text { Maxillary } 1^{\text {st }} \\
\text { molar\% }\end{array}$ & $\begin{array}{c}\text { Mandibular }^{\text {st }} \\
\text { molar\% }^{\text {so }}\end{array}$ \\
\hline $7-8$ & 37.9 & 55.1 \\
\hline $9-10$ & 70.8 & 91.6 \\
\hline $11-12$ & 76.5 & 91.4 \\
\hline Total & 64 & 80 \\
\hline
\end{tabular}

Table (4) shows the occurrence of bilateral caries severity by age. Result showed for the total sample $\mathrm{D}_{2}$ was higher in the upper jaw and lower jaw 26\%-20\% respectively. Concerning each age group the same result was found.

Table 4: The occurrence of bilateral caries severity by age

\begin{tabular}{|c|c|c|c|}
\hline $\begin{array}{c}\text { Age } \\
\text { groups }\end{array}$ & Variables & $\begin{array}{c}\text { Maxillary 1 } \\
\text { molar\% }\end{array}$ & $\begin{array}{c}\text { Mandibular } \text { 1 }^{\text {st }} \\
\text { molar\% }\end{array}$ \\
\hline \multirow{4}{*}{$7-8$} & $\mathrm{D}_{1}$ & 3.4 & 3.4 \\
\cline { 2 - 4 } & $\mathrm{D}_{2}$ & 13.7 & 17.2 \\
\cline { 2 - 4 } & $\mathrm{D}_{3}$ & 3.4 & 13.7 \\
\cline { 2 - 4 } & $\mathrm{D}_{4}$ & 3.4 & 0 \\
\hline \multirow{4}{*}{$9-10$} & $\mathrm{D}_{1}$ & 4.1 & 0 \\
\cline { 2 - 4 } & $\mathrm{D}_{2}$ & 45.8 & 20.8 \\
\cline { 2 - 4 } & $\mathrm{D}_{3}$ & 0 & 12.5 \\
\cline { 2 - 4 } & $\mathrm{D}_{4}$ & 4.1 & 0 \\
\hline \multirow{4}{*}{ Total } & $\mathrm{D}_{1}$ & 8.5 & 4.2 \\
\cline { 2 - 4 } & $\mathrm{D}_{2}$ & 23.4 & 21.2 \\
\cline { 2 - 4 } & $\mathrm{D}_{3}$ & 2.1 & 14.8 \\
\cline { 2 - 4 } & $\mathrm{D}_{4}$ & 0 & 10.6 \\
\cline { 2 - 4 } & $\mathrm{D}_{1}$ & 6 & 3 \\
\cline { 2 - 4 } & $\mathrm{D}_{2}$ & 26 & 20 \\
\cline { 2 - 4 } & $\mathrm{D}_{3}$ & 2 & 5 \\
\hline
\end{tabular}

\section{Discussion}

Results showed higher percentage of bilateral caries in the total population which was in agreement with other study[10].However concerning the caries bilateral the present study wasfound higher in mandibular teeth than maxillary teeth this agreed with other study done among Saudi school children [13] ; This could be that in majority of children mandibular first permanent molar erupts slightly earlier than its maxillary counterpart, hence mandibular first permanent molar being exposed to the oral environment for a longer period of time, making it more susceptible to caries than maxillary first permanent molar [14]. $D_{2}$ lesions were most common occurrence bilaterally this agree withJazrawiin 2009 who found the same result [15]. The $D_{1}$ $\mathrm{D}_{4}$ criteria advocate many advantages over the caries criteria used in the past. These include a better means of estimating the need for and recommending appropriate preventive and restorative treatment measures, a more sensitive measure of assessing change in caries status and better means of predicting future caries [16, 17, 18].The caries bilaterally was higher in older children as compared to younger children. This was expected; as age increases and cariogenic factors continue to exist, more and more contralateral teeth become carious[9].

\section{Conclusions}

The cariesseverity information would assist in the determination of treatment needs and preventive efforts required in this population. A high bilateral occurrence demands careful prevention strategies including fissure sealants, topical fluoride applications .The knowledge of caries pattern would help clinicians in the formulation of appropriate treatment strategies. It could be deduced from the above results and discussion that considerable efforts are required in prevention of dental caries in these children. There is a lot of untreated caries, which needs immediate

\section{Volume 6 Issue 12, December 2017}




\section{International Journal of Science and Research (IJSR) \\ ISSN (Online): 2319-7064 \\ Index Copernicus Value (2016): 79.57 | Impact Factor (2015): 6.391}

attention. A preventive program should be developed early in life.

\section{References}

[1] Saleh KM. Dental caries and treatment needs of primary and permanent teeth for children attending pedodontic clinic. Al- Rafidain Dent J. 2007; 7(1): 80-87.

[2] Ahovuo-Saloranta A, Hiiri A, Nordblad A. Pit and fissure sealants for preventing dental decay in the permanent teeth of children and adolescents. Cochrane Database Syst Rev 2008; 4:CD001830.

[3] Brekhus PJ. Investigation of loss of human teeth. J Am Dent Assoc. 1928; 15:679-690.

[4] Knuston JW, Klein H. Studies of dental caries, part IV: tooth mortality in elementary school children. Pub Health Rep. 1938; 53:1021-1032.

[5] Halikis SE. A study of dental caries in a group of Western Australian childrenIVThebilaterally of dental caries. Aust Dent J. 1965; 10:371-375.

[6] Wei SH, Holm AK, Tong LS, Yuen SW. Dental caries prevalence and related factors in 5-year-old children in Hong Kong. Pediatr Dent. 1993; 15:116-119.

[7] Nainar SMH, Wyne AH. Caries pattern of high caries pre-school children attending a dental clinic in Riyadh, Saudi Arabia. Saudi Dent J. 1998; 10:80-83.

[8] Wyne AH. The phenomenon of caries bilaterality in Saudi pre-school children. Egypt Dent J. 2000; 46:189191.

[9] Wyne AH. The bilateral occurrence of dental caries among 12-13 and 15-19 year-old school children. J Contemp Dent Pract. 2004; 1:42-52.

[10] Sadeghi, M. (2007): Prevalence and Bilateral Occurrence of First Permanent Molars Caries in 12Year-Old Students in Rafsanjan, Iran. Journal of Dental Research Dental Clinics Dental Prospects 1, 34-40

[11] World Health Organization (1997): Oral Health Surveys: Basic Methods. 3rd ed. Geneva: WHO.

[12] Manji F, Fejerkuv, Baelum V. 1989. Pattern of dental caries in adult rural population. Caries Res. 23, 55-69.

[13] Wyne, A. H., Chohan, A. N., Jastaniyah, N., \& AlKhalil, R. (2008). Bilateral occurrence of dental caries and oral hygiene in preschool children of Riyadh, Saudi Arabia. Tropical Dental Journal, 31(124), 19.

[14] Togoo R, Yaseen S, Zakirulla M, Al Garni F, Khorage A, Meer A. Prevalence of first permanent molar caries among 7-10 years old school Going boys in Abha city, Saudi Arabia. J International Oral Health 2011; 3:29-34.

[15] Jazrawi KH. Evaluation of dental caries prevelance among Kindergartens Children in Mosul city center. Al-Rafidain Dent J. 2009; 9(1):120-130.

[16] Ismail AI. Clinical diagnosis of precavitated carious lesions.Community Dent Oral Epidemiol.1997; 25: 1323.

[17] Pitts NB. Diagnostic tools and measurements - impact on appropriate care. Community Dent Oral Epidemiol.1997; 25: 24-35.

[18] Warren JJ, Levy SM, Kanellis MJ. Dental caries in the primary dentition: Assessing prevalence of cavitated and non-cavitated lesions. J Public Health Dent. 2002; 62(2): 109-114.

Volume 6 Issue 12, December 2017 www.ijsr.net 